\title{
O patrimônio cultural brasileiro em debate: a ação do Conselho Federal de Cultura (1967-1975)
}

Tatyana de Amaral Maia*

\section{Resumo}

O Conselho Federal de Cultura, CFC, foi o principal órgão responsável pelas políticas culturais entre 1967 e 1975. O CFC era formado por vinte e quatro intelectuais com o objetivo de organizar o setor cultural e elaborar o inédito Plano Nacional de Cultura. Suas principais políticas foram organizadas em favor da defesa do patrimônio cultural brasileiro. O objetivo deste artigo é investigar a ação do CFC e sua compreensão acerca do patrimônio e da cultura nacional na ditadura civil-militar.

Palavras-chave: Políticas culturais/Brasil. Preservação do patrimônio cultural. Patrimônio cultural e Estado.

The brazilian cultural heritage in debate: the action of Conselho Federal de Cultura (1967-1975)

\begin{abstract}
The Conselho Federal de Cultura, CFC, was the main organ responsible for the cultural policies between 1967 and 1975. The CFC was formed by twenty-four intellectuals with the objective of organizing the cultural sector and elaborating the original Plano Nacional de Cultura. Your cultural policies were organized for defense of brazilian cultural patrimony. The objective this article is investigate the action to CFC and your comprehension about patrimonial and national culture in the civilmilitary dictatorship.
\end{abstract}

Key-Words: Cultural policies/Brazil. Cultural heritage preservation. Cultural heritage and State. 


\section{Introdução}

Os debates sobre a questão do patrimônio no Brasil e, principalmente, a função do Estado na identificação, seleção, preservação e divulgação desse patrimônio remontam à década de 1930. A noção de patrimônio adquiriu significados políticos, sendo considerado como elemento essencial na construção do sentimento nacional.

Desde os anos de 1920, os intelectuais ligados ao movimento modernista, às direções dos museus nacionais e aos governos estaduais dedicavam-se à questão da proteção do patrimônio (FONSECA, 2005, p. 81). A ingerência federal na esfera cultural foi intensificada a partir de 1930, após a criação do Ministério da Educação e Saúde (MES), posteriormente, Ministério da Educação e Cultura (1953). Foram institucionalizadas diversas áreas da cultura como os setores dedicados ao teatro, livro, folclore, patrimônio artístico, cinema, radiodifusão educativa, além dos setores dedicados ao controle dessa produção através do estabelecimento de mecanismos de censura. A área cultural do MES, na gestão de Gustavo Capanema (1934-1945), recrutou diversas personagens do movimento modernista, que permaneceram prestando serviços no setor mesmo após o fim do primeiro governo Vargas (SCHWARTZMAN; BOMENY; COSTA, 2000, p. 97). Observamos, então, que a atuação dos intelectuais no universo político, especialmente no interior do Estado, atravessa a ditadura civil-militar (1964-1985), preservando a relativa autonomia desses atores em relação ao direcionamento político empreendido pelo Estado.

O Ministério da Educação e Cultura agregou, em instâncias por ele criadas, importantes grupos intelectuais e técnicos durante a ditadura civil-militar (19641985), dentre os quais: o Conselho Federal de Cultura (1966), o Departamento de Assuntos Culturais (1970), a Fundação Nacional de Arte (1975) etc. Esses núcleos tinham como objetivo central orientar as políticas culturais a serem executadas no país.

O objetivo deste artigo é investigar as ações do Conselho Federal de Cultura, CFC, em favor da proteção do patrimônio cultural entre 1967 e 1975. Busca-se compreender como o CFC está alinhado ao projeto de proteção do patrimônio defendido pelos intelectuais modernistas atuantes no MEC desde a década de 1930. O Conselho propôs como política para o setor cultural a adoção de uma ação 
integrada entre estados, municípios e União, mantendo a hierarquia dos órgãos federais na definição dos princípios que regeriam os processos de identificação, seleção, guarda e divulgação dos conjuntos que comporiam o patrimônio nacional.

A coletânea de artigos organizados por Sérgio Miceli, Estado e Cultura no Brasil, pretende discutir o papel interventor dos governos militares nas políticas culturais a partir de dois eixos analíticos: as relações específicas estabelecidas entre política e cultura em governos autoritários; e, as disputas entre duas vertentes no interior do MEC: a "vertente patrimonialista" e a "vertente executiva" (MICELI, 1984).

Para Miceli, os grupos passaram a disputar a orientação das políticas culturais dividindo-se entre esses dois pólos. As discussões oscilaram entre a defesa do patrimônio e a implementação de políticas de fomento da produção artística nacional. A corrente patrimonialista apoiava a conservação do patrimônio como forma de valorização da cultura nacional, propondo-a como meta-síntese da política cultural. Do outro lado, a corrente executiva apontava para a necessidade do Estado impulsionar, orientar e financiar as produções artísticas, através da criação de um órgão específico para os assuntos relacionados à cultura, opondo-se à tradição das políticas culturais dedicadas exclusivamente à proteção do patrimônio nacional (MICELI, 1984, p. 67).

Em Cultura Brasileira e Identidade Nacional, Renato Ortiz define a existência de dois grupos concorrentes no setor cultural: a indústria dos meios de comunicação de massas, formada por grupos relacionados ao processo de consolidação do capitalismo tardio no Brasil; e, a existência de círculos intelectuais no interior do MEC identificados com a defesa do patrimônio e a valorização da "cultura nacional" (ORTIZ, 1986).

Além de considerarmos esses posicionamentos, nos apoiamos, especialmente, nas análises de Maria Cecília de Londres Fonseca, José Reginaldo Santos Gonçalves e Angela de Castro Gomes que demonstram a relação entre as políticas culturais, destinadas à preservação da memória, e a construção da identidade nacional. (FONSECA, 2005; GONÇALVES, 1996; GOMES, 1996). 
Este artigo está criticamente alinhado a esta produção historiográfica e sociológica dedicada às políticas culturais, sobretudo, àquelas destinadas à compreensão das políticas de preservação de patrimônio no Brasil. Dessa forma, acreditamos que os projetos culturais organizados pelos intelectuais do CFC só podem ser compreendidos à luz das orientações teóricas do grupo, especialmente, do modernismo e de suas inter-relações com os setores concorrentes no interior do MEC.

\section{Conselho Federal de Cultura}

O Conselho Federal de Cultura foi criado pelo decreto-lei n. 74, de 12 de novembro de 1966, e funcionou no Palácio da Cultura, no Rio de Janeiro, até sua extinção em 1990. O início de suas atividades ocorreu em janeiro de 1967. O órgão tinha caráter normativo e de assessoramento ao ministro de Estado. A criação do Conselho Federal de Cultura teve como objetivo principal institucionalizar a ação do Estado no setor cultural. O período de 1967 até 1975 foi o mais profícuo para a atuação dos conselheiros. O CFC, até 1975, foi o órgão responsável por intervenções sistemáticas que produziram no interior do aparelho estatal uma rotina burocrática fundamental na institucionalização do setor. Contudo, a partir da gestão Ney Braga, outras instituições passaram a concorrer com o CFC promovendo intervenções mais significativas no setor cultural (MAIA, 2010, p. 15).

O CFC foi estruturado em quatro Câmaras: Artes, Ciências Humanas, Letras e Patrimônio Histórico e Artístico. Esta divisão era considerada decisiva pela comissão que elaborou o projeto do Conselho por constituir os elementos considerados definidores da cultura nacional. Além disso, os conselheiros organizaram a Comissão de Legislação e Normas para garantir o suporte jurídico necessário à apresentação de portarias, anteprojetos de lei ou resoluções.

Os membros do Conselho foram divididos entre as Câmaras de acordo com sua formação e experiência profissional. Os conselheiros eram, em sua maioria, escolhidos pelo presidente do CFC e nomeados pelo presidente da República, cuja permanência no cargo, a princípio, vigorava durante o mandato de dois anos do presidente do Conselho. Na prática, os conselheiros eram reconduzidos ao cargo a cada nova posse dos presidentes do Conselho. No período pesquisado (1967-1975) 
o Conselho teve três presidentes: Josué Montello (1967-1968), Arthur Cezar Ferreira Reis (1969-1972) e Raymundo Moniz de Aragão (1973-1974). Os membros fundadores do CFC foram: Presidente do Conselho - Josué Montello; Câmara de Artes - Clarival do Prado Valladares (presidente), Ariano Suassuna, Armando Sócrates Schnoor, José Candido Andrade Muricy, Octávio de Faria, Roberto Burle Marx; Câmara de Letras - Adonias Aguiar Filho (presidente), Cassiano Ricardo, João Guimarães Rosa, Moyses Vellinho, Rachel de Queiroz; Câmara de Ciências Humanas - Arthur Cezar Ferreira Reis (presidente), Augusto Meyer, Djacir Lima Menezes, Gilberto Freyre, Gustavo Corção, Manuel Diégues Júnior; Câmara do Patrimônio Histórico Artístico Nacional - Afonso Arinos de Mello Franco (presidente), Hélio Vianna, Dom Marcos Barbosa, Pedro Calmon, Raymundo Castro Maya, Rodrigo Mello Franco de Andrade.

Durante o período de 1967 até 1975 quarenta intelectuais exerceram o cargo de conselheiro. Dos vinte quatro membros fundadores, dezesseis conselheiros permaneceram atuantes no Conselho até 1975. Para os intelectuais, o Estado tornou-se a instituição central para a realização de qualquer projeto político a ser efetivado no país. O CFC pretendia construir um aparato burocrático dedicado exclusivamente à área cultural e (re)definir as diretrizes para promoção, preservação e difusão da cultura no país através da execução de uma política de proteção cultural. O objetivo do Conselho era fortalecer esses espaços considerados fundamentais na preservação da memória nacional.

Por força do decreto-lei de sua criação, o novo órgão do Ministério da Educação e Cultura tinha apenas o caráter normativo, consultivo e fiscalizador, tal como definido no seu Regimento. Na prática, o Conselho tornou-se encarregado pela distribuição das verbas; financiamento de instituições públicas e privadas do setor cultural; assessoramento ao ministro da Educação e Cultura; definição das áreas de atuação do Estado; realização de convênios com instituições; elaboração de regulamentos e resoluções; organização de campanhas nacionais de cultura; e defesa do patrimônio cultural. No Regimento do Conselho ficaram definidas as linhas de atividades e as instituições a elas relacionadas: as instituições nacionais de cultura do MEC; as instituições estaduais de cultura; os setores culturais das universidades; e os institutos particulares reconhecidos pelo Conselho como de utilidade pública. Dessa 
forma, o CFC passou a ter uma atuação ampla, importante e centralizadora na orientação das políticas culturais até 1975, privilegiando aquelas ações que melhor institucionalizassem o setor cultural no interior do aparelho estatal.

Para os membros do Conselho a ação estatal no setor deveria priorizar as áreas consideradas essenciais da cultura nacional: os conjuntos arquitetônicos, as obras da literatura, as comemorações dos acontecimentos históricos singulares, as manifestações folclóricas. Para cumprir tamanha tarefa, incorporou e ampliou o modelo de preservação do patrimônio elaborado pelo Serviço do Patrimônio Histórico e Artístico Nacional, criado e dirigido por Rodrigo Melo Franco de Andrade (1936-1969), minimizando seus investimentos nos setores de produção de bens culturais de massa.

\section{A incorporação dos pressupostos teóricos do SPHAN às políticas do CFC: continuidades e rupturas}

No interior do Ministério da Educação e Saúde, posteriormente, Ministério da Educação e Cultura (1953) a instituição cultural melhor aparelhada era o Serviço do Patrimônio Histórico e Artístico Nacional, criado por Gustavo Capanema, em 1937, sob a direção de Rodrigo Melo Franco de Andrade. O SPHAN, posteriormente DPHAN e, a partir da Reforma Administrativa do MEC de julho de 1970, IPHAN, foi o órgão responsável pela definição de uma inédita política de preservação federal. A longa gestão de Rodrigo Melo Franco de Andrade é considerada um marco na orientação político-burocrática daquele órgão. Na década de 1930, Rodrigo Melo Franco de Andrade é convidado pelo ministro da Educação e Saúde Francisco Campos para ocupar a chefia do gabinete do ministro no MES. Em 1936, já na administração de Gustavo Capanema, formulou o projeto com as orientações definitivas do novo órgão, apoiando-se num anteprojeto apresentado originalmente por Mário de Andrade. Rodrigo Melo Franco de Andrade permaneceu no cargo até 1967 e contou com a colaboração, de intelectuais como Alceu Amoroso Lima, Lúcio Costa, Mário de Andrade, Manuel Bandeira, Sérgio Buarque de Hollanda, entre outros, além de futuros membros do Conselho Federal de Cultura: Afonso Arinos, Arthur Cesar Reis, Augusto Meyer, Gilberto Freyre, Renato Soeiro (FONSECA, 2005). Seu discípulo Renato Soeiro substituiu-o na direção do SPHAN em 1967, e após 1969, passou a ocupar seu lugar no Conselho Federal de Cultura. 
O SPHAN-DPHAN-IPHAN não foi o único órgão criado na década de 1930 para tentar organizar e ampliar a participação do Estado na esfera cultural, tampouco o único setor da área da cultura que despertou o interesse estatal. Contudo, foi o órgão que respondeu de forma mais eficaz às demandas do executivo.

[...] o IPHAN, ao preservar o patrimônio histórico e artístico, deveria responder a pelo menos três desafios. Primeiro, ao desafio político de estimular e canalizar a participação social na preservação cultural. Segundo ao desafio ideológico de identificar e forjar um 'patrimônio cultural brasileiro' (...). Finalmente, ao desafio administrativo de cunhar e consolidar uma estrutura estatal burocrático-cultural, nacional e eficiente. (FALCÃO, 1984, p. 27).

Ao longo dos trinta primeiros anos o SPHAN conseguiu consolidar uma estrutura administrativa e definir a noção de preservação do patrimônio, apesar dos recursos insuficientes destinados àquela instituição. A gestão de Rodrigo Melo Franco de Andrade, considerada a "fase heróica", foi pautada por discursos de defesa do patrimônio, cujo traço principal é a valorização dos registros do passado como elementos autênticos e singulares da identidade cultural brasileira diante das demais nações. Conforme propõe o antropólogo José Reginaldo Santos Gonçalves,

\footnotetext{
Este projeto era implementado por uma nova elite de bases urbanas - em oposição às velhas elites agrárias - que veio a dirigir o país sob a orientação modernizadora, após a revolução de trinta. Nessa ideologia, assume o primeiro plano o projeto de construção de uma nova nação, através da modernização das estruturas econômicas, políticoadministrativas e culturais. Esse projeto veio a ser implantado por meio de uma burocracia estatal, centralizada e autoritária, controlada a partir de um pacto entre segmentos das velhas e novas elites. (GONÇALVES, 1996, p. 39).
}

Ao realizarmos uma leitura crítica das análises dedicadas às políticas de proteção do patrimônio no Brasil, selecionamos dois pesquisadores que sintetizam as discussões sobre a presença de intelectuais no SPHAN e suas relações com o Estado. Para o antropólogo José Reginaldo Santos Gonçalves, o caráter tradicionalista presente na produção discursiva do diretor do SPHAN compõe o cenário autoritário e modernizador projetado pela ditadura de Vargas, promovendo uma articulação entre as diretrizes gerais do Estado Novo e a atuação do SPHAN. Em contrapartida, a 
socióloga Maria Cecília L. Fonseca propõe a existência de uma "autonomia" no interior do SPHAN que produziu uma política de preservação mais integrada à "concretização de um projeto modernista" do que ao processo de "exortação cívica que caracterizava a atuação do ministério na área educacional” (FONSECA, 2005, p. 98). A socióloga credita essa "autonomia" da instituição à legitimidade conquistada através da habilidade de seu diretor em reunir pesquisadores das mais diversas formações e insistir na utilização de critérios científicos modernos e, principalmente, "a imagem de uma instituição coesa, desvinculada dos interesses políticospartidários [...]" (FONSECA, 2005, p. 104). Uma análise crítica dessa historiografia, nos permite compreender que ambas as perspectivas analíticas podem ser vislumbradas nas complexas relações estabelecidas entre essa intelectualidade e a cúpula do executivo. Assim sendo, proponho que se o SPHAN não pode ser reduzido a um órgão divulgador do projeto ideológico varguista, havia uma proximidade entre as diretrizes do executivo e a ação da instituição, conforme verificado tanto por José Reginaldo Santos Gonçalves como também por Maria Cecília Fonseca. Dessa forma, a existência de uma relativa autonomia do órgão, se comparado à intervenção sofrida pelo setor educacional, não significou que suas ações e definições sobre o patrimônio divergissem da produção simbólica elaborada pelo Estado Novo:

Na medida em que o Sphan foi um dos braços do ministério de Capanema, era inevitável algum compromisso entre os intelectuais que atuavam na instituição e no regime. Suponho que esse compromisso se exprimia basicamente numa demarcação de limites e numa relação de reciprocidade: ou seja, a autonomia de que gozava o Sphan dentro do MES tinha como contrapartida implícita o não envolvimento daqueles intelectuais em outras esferas de governo, inclusive aquelas que em princípio - como censura e propaganda - afetavam profundamente a vida cultural. (FONSECA, 2005, p. 121).

O SPHAN cristalizou uma concepção de cultura nacional a partir da preservação das obras arquitetônicas e dos centros históricos. Conforme demonstra Maria Cecília L. Fonseca, até a década de 1960, o SPHAN manteve-se centrado no patrimônio de pedra e cal; a prática dos tombamentos, principal área de atuação do órgão, privilegiou a definição estética, seguida do valor histórico, elegendo obras consideradas de alto valor artístico, hierarquizando-as conforme o estilo: barroco, neoclássico, moderno e eclético (FONSECA, 2005, p. 115). Essa visão do 
patrimônio como elemento indispensável à civilização e à modernidade, institucionalizada na gestão de Rodrigo Melo Franco de Andrade, foi apropriada pelos integrantes do CFC e manteve-se incorporada às suas práticas, afinal, muitos daqueles que participaram do SPHAN, integraram-se ao CFC. Contudo, o Conselho ampliou a noção de patrimônio, incorporando ao conceito os hábitos, costumes, danças, modos de agir e pensar, invenções nas áreas científicas e artísticas etc. Essa definição ampla do patrimônio foi apresentada nas Diretrizes para uma política cultural, em 1973, documento responsável por ordenar o papel do Estado na cultura, dando-Ihe fundamentação teórica, constituindo uma definição sobre a função da política cultural e seus pilares de ação:

constituído das tradições históricas e dos hábitos e costumes estratificados; das criações artísticas e literárias mais representativas do espírito criador brasileiro; das realizações técnicas e científicas de especial significação para a humanidade; das cidades, conjuntos arquitetônicos e monumentos de significação histórica, artística, cívica ou religiosa; das jazidas arqueológicas, das paisagens mais belas ou típicas do território pátrio; das idéias e ideais partilhados pelos brasileiros (CONSELHO FEDERAL DE CULTURA, 1973, p. 60).

A atuação do Conselho Federal de Cultura está diretamente relacionada à sua percepção do papel do Estado no setor cultural. Tomamos o discurso dos membros do CFC como integrante do discurso estatal sobre o seu papel e a função da cultura, ainda que em alguns momentos haja uma tensão entre a proposta do CFC e as orientações da cúpula do executivo. Para o Conselho, a intervenção do Estado na cultura era essencial na produção de bens culturais e na preservação do patrimônio. O Estado era o único agente capaz de criar uma infraestrutura que assegurasse as condições necessárias para a liberdade criadora nas diversas formas de expressão artística. Neste sentido, o Estado não aparece como um censor da produção cultural, ao contrário, ele garante que o setor cultural não sofrerá qualquer pressão que oriente, subordine ou limite sua produção.

O que pretendemos afirmar e concluir, no entanto, é que somos ainda parte do mundo subdesenvolvido, de que nos esforçamos para sair, e que ainda não é possível prescindir da intervenção do Estado na movimentação da cultura e na criação de uma infra-estrutura capaz de assegurar condições que Ihe permitam realizar-se plenamente, liberta de qualquer 
interferência que the perturbe, limite ou discipline a evolução. Nos países novos ou que ainda não lograram uma participação maior nos grandes lances da civilização universal, o papel do Estado é fundamental, o que não significa a contenção da criatividade ou seu condicionamento a fórmulas e postulados ideológicos, impostos pelo poder público como sucede em algumas nações. (REIS, 1973, p. 13).

As funções centrais do CFC foram definidas e hierarquizadas já no documento de sua criação: preservar o patrimônio e elaborar uma política nacional para o setor. $\mathrm{O}$ decreto-lei n. 74 , de criação do Conselho, no artigo $2^{\circ}$, estabeleceu vinte objetivos para o novo órgão, dentre os quais destacamos: a) formular a política nacional de cultura; b) articular-se a órgãos públicos e a universidades dedicados à cultura e à educação para execução de programas culturais; c) atuar junto aos órgãos competentes para a defesa e preservação do patrimônio; d) conceder auxílios às instituições culturais oficiais ou particulares de utilidade pública para conservação e restauração de seu patrimônio histórico, artístico ou bibliográfico, e ainda, a execução de projetos de difusão da cultura; e) promover campanhas nacionais; f) publicar boletim informativo; g) estimular a criação de Conselhos Estaduais de Cultura; h) elaborar o Plano Nacional de Cultura; i) assessorar quando solicitado o ministro da Educação e Cultura; j) auxiliar a realização de exposições, espetáculos, conferências, debates, festivais, que promovam a divulgação cultural e aprimorem o conhecimento sobre as regiões brasileiras (DECRETO-LEI..., 1967, p. 107-110).

Esse amplo conjunto de objetivos indica que o Conselho exerceria uma função executiva e centralizadora na organização das ações culturais. A articulação dessas várias competências formaria a política cultural do MEC. Neste artigo, o conceito de políticas culturais está amparado na definição proposta por Néstor Garcia Canclini e pressupõe a existência de uma ação estatal organizada, contínua, com recursos destinados exclusivamente ao setor e que atenda, ainda que de forma hierarquizada, aos múltiplos espaços que compõe a área (GARCÍA CANCLINI, 1987, p. 26).

Na prática da rotina burocrática, a importância do Conselho Federal de Cultura reside na sua experiência inédita de organização de um órgão destinado exclusivamente às diversas áreas da cultura, cuja maior conquista foi a 
institucionalização inicial do setor com a criação do Departamento de Assuntos Culturais - embrião da Secretaria de Assuntos Culturais e do Ministério da Cultura. Dessa forma, apesar de suas limitações financeiras, a experiência do Conselho possibilitou a formação de um espaço político exclusivamente destinado aos setores da área cultural no interior do MEC. No campo político, os conselheiros concretizaram no interior do Estado experiências acumuladas em outros espaços de sociabilidade aos quais estavam integrados como as direções dos museus, a Academia Brasileira de Letras e o Instituto Histórico e Geográfico Brasileiro. Mesmo com ações pontuais, devido à falta de recursos necessários ao desenvolvimento de projetos de grande envergadura, o CFC produziu ações que se tornaram valiosas estratégias nas disputas pela autoridade sobre a definição da cultura nacional no interior do campo intelectual e ampliaram a institucionalização do setor através da criação de Conselhos Regionais de Cultura; da publicação de obras específicas; e do investimento no reaparelhamento das instituições culturais.

O Conselho Federal de Cultura atuou como catalisador dos anseios de agências e instituições do Ministério da Educação e Cultura, especialmente, ao se tornar o principal responsável pela distribuição de verbas para o setor. As instituições e órgãos do MEC passaram a estar sob o manto protetor do Conselho, numa relação de aparente dependência. Entretanto, muitos dos diretores ou ex-diretores das instituições de cultura eram membros do Conselho e sua criação foi uma estratégia para a institucionalização da área cultural. Essa relação de aparente subordinação esconde a capacidade de organização política dos diretores das instituições de cultura que ao se agregarem em torno de um conselho puderam negociar suas demandas diretamente com o ministro e enviar diversos anteprojetos de lei ao Congresso Nacional, como no caso, dos anteprojetos de lei de reforma das instituições nacionais de cultura que previam autonomia administrativa e financeira a essas instituições.

É no âmbito do patrimônio que o Estado exerce uma das suas principais ações na cultura e essa definição foi elaborada pelos ideólogos do Conselho e ratificadas pelos membros que comporiam o CFC entre 1967 e 1975. O conceito de cultura brasileira proposto pelo Conselho Federal de Cultura compreende a cultura nacional como um patrimônio formado desde o processo de conquista e colonização 
portuguesa, portanto, definida por aspectos de longa duração e singulares que permitem a distinção do Brasil em relação às demais nações.

Ora, há, no Brasil, uma cultura, a cultura brasileira, que é a construção que vimos promovendo, nós, o povo brasileiro, no continente-arquipélago que constituímos e nos distingue no cenário mundial. A cultura brasileira, com cerca de quinhentos anos de passado, (...), é patrimônio de que nos podemos orgulhar porque é fruto de nossa constância, de nossa dramática atividade criadora como sociedade que se afirma desde a luta contra a natureza, rica e muitas vezes difícil, à construção de centros de revolução urbanística dos tempos novos que o mundo vive, como é o caso de Brasília. (REIS, 1973, p. 12).

O patrimônio nacional, tal como proposto pelo CFC, incluía as obras artísticas e arquitetônicas de valor histórico, os museus, as bibliotecas, os teatros, as academias de letras e os institutos históricos, as cerimônias cívicas, as grandes obras da literatura, as festas populares, os centros históricos. Assim, como afirma Nestor Canclini,

As únicas operações possíveis - preservá-lo, restaurá-lo, difundi-lo - são a base mais secreta da simulação social que nos mantêm juntos (...). A perenidade desses bens leva a imaginar que seu valor é inquestionável e torna-os fontes do consenso coletivo, para além das divisões entre classes, etnias e grupos que cidem a sociedade e diferenciam os modos de apropriar-se do patrimônio. (GARCÍA CANCLINI, 2000, p. 160).

A questão do patrimônio tornou-se a grande bandeira de atuação do Conselho Federal de Cultura. A cultura brasileira era um patrimônio ameaçado pela falta de infra-estrutura e investimentos. Essa perspectiva de patrimônio ameaçado, retratado pelo CFC nos encontros promovidos com representantes dos governos federal, estados e municípios está associada às orientações das políticas culturais desenvolvidas pelo SPHAN desde o primeiro governo Vargas (1937-1945), do qual muitos conselheiros participaram.

A historiadora Angela de Castro Gomes destaca a importância do "passado" na produção cultural estadonovista, fundamental no campo político para a construção de um imaginário social que se identificasse com o Estado nacional. Para a autora, a 
valorização do passado deveria responder simultaneamente a dois lugares: aos eventos únicos e ao conjunto de elementos estruturais que formavam a sociedade brasileira. Essas duas faces do passado caracterizavam o "espírito nacional" ventilado pelo Estado Novo (GOMES, 1996, p. 141).

O processo de "recuperação do passado", proposto por Angela de Castro Gomes, pode ser associado à noção de "perda do patrimônio", definida por José Reginaldo Santos Gonçalves. O passado, fruto da simbiose entre as tradições e os eventos singulares, estaria ameaçado pelo descaso com o patrimônio, desfigurando a nação. A "retórica da perda", de José Reginaldo Santos Gonçalves (1996), articulada à necessidade de "recuperação do passado" pressupõe que a identidade brasileira é identificada por elementos concretos e objetivos, procurando numa suposta essência nacional os referenciais que precisam ser reorganizados e resguardados (GONÇALVES, 1996, p. 89). Dessa forma, a valorização do passado, a urgência de sua recuperação e a denúncia da perda do patrimônio compõem o mesmo cenário discursivo: a necessidade de centralização das ações estatais.

A tarefa principal do Conselho era centralizar as ações no setor cultural, tornando-o uma área de permanente atuação do Estado através de políticas de proteção da cultura. Para isso, foram organizados, sob os auspícios do CFC, encontros com autoridades do setor cultural, convocando estados e municípios para articularem seus esforços ao da União em defesa do ameaçado patrimônio cultural através da constituição de um "sistema nacional de cultura".

Assim, a investigação dos Encontros realizados pelo CFC pretende demonstrar como o projeto modernista para a proteção do patrimônio adotado pelo Estado a partir da criação do SPHAN foi incorporado pelo Conselho durante a ditadura civilmilitar.

\subsection{A criação de um sistema integrado para a cultura: a "I Reunião Nacional} dos Conselhos de Cultura" (1968)

O CFC estimulou a criação dos conselhos estaduais de cultura (CECs) e dos conselhos municipais de cultura (CMCs) considerados fundamentais para 0 planejamento e a execução de políticas culturais que abrangessem todo o território 
nacional. A criação de conselhos estaduais e municipais era necessária à formação de um "sistema nacional de cultura" capaz de atender às diversas demandas regionais constitutivas da nacionalidade. A base desse sistema seriam os conselhos municipais de cultura articulados com os conselhos estaduais. Para fortalecer esses conselhos, foi organizada a "I Reunião Nacional dos Conselhos de Cultura", realizada entre os dias 22 e 24 de abril de 1968, em Brasília. O decreto n. 62.256, de 12 de fevereiro de 1968, assinado pelo presidente da República Arthur da Costa e Silva convocou para a "I Reunião Nacional dos Conselhos de Cultura" os membros do Conselho Federal de Cultura, os diretores das instituições nacionais de cultura vinculadas ao Conselho e os representantes dos Conselhos Estaduais de Cultura ou seus similares. Foram convidadas outras autoridades do MEC e dos Ministérios do Planejamento e das Relações Exteriores, além das comissões de educação e cultura do Senado Federal e da Câmara dos Deputados. Ao CFC coube coordenar todas as atividades da reunião cujo objetivo central seria o "estudo das questões pertinentes à articulação, à coordenação e à execução do Plano Nacional de Cultura" (DECRETO..., 1968, p. 67).

Os conselhos estaduais deveriam estar articulados às diretrizes gerais do Conselho Federal de Cultura, mas a autonomia de cada conselho estadual ou municipal foi preservada. A Reunião contou com a participação de vinte e dois representantes dos Conselhos estaduais, muitos dos quais foram criados às pressas, sem estrutura ou verba definida, existindo apenas para cumprir a exigência federal e disputar os poucos recursos destinados ao CFC. Às vésperas da Reunião, o Conselho Estadual da Paraíba enviou um telegrama ao CFC informando que apesar de seus três anos de existência não possuía dotação orçamentária. Os representantes dos estados de Alagoas e do Sergipe informavam, respectivamente, que os membros do CEC/AL e CEC/SE haviam sido empossados há poucos dias. Os telegramas dos CECs enviados um mês antes da reunião, que se pretendia anual, denunciavam a precariedade dos estados na organização do setor cultural e anunciavam os limites daquele encontro, que foi mais declaratório das intenções do CFC do que capaz de planejar ações concretas devido à debilidade dos conselhos estaduais ainda em estruturação. Alguns conselhos estaduais e municipais lograram êxito como, no caso, dos conselhos estaduais dos estados do Pará, Pernambuco, Rio de Janeiro e São Paulo, além dos conselhos municipais de São José do Rio Preto (SP) e, 
principalmente, do estado do Rio de Janeiro - com vinte conselhos municipais -, que promoveram dois encontros estaduais em 1972 e 1973. O CEC/GO e o CEC/RJ elaboraram seus respectivos planos estaduais de cultura à semelhança dos anteprojetos do Plano Nacional de Cultura elaborados pelo CFC. Alguns representantes do CFC participavam dos conselhos estaduais como, por exemplo, Gilberto Freyre (presidente do CEC/PE) e Ariano Suassuna que integravam o Conselho Estadual de Pernambuco. Os conselhos estaduais também eram convocados para colaborarem com alguns projetos do CFC como o Calendário Cultural, a comemoração de efemérides, a obra História da Cultura Brasileira indicando a relação de reciprocidade existente entre o conselho federal e os conselhos estaduais.

No discurso de abertura da "I Reunião", o ministro da Educação e Cultura Tarso Dutra reforçou a ideia da criação do CFC, pelo já falecido marechal Humberto Castelo Branco, como uma demonstração a todo o país de uma das funções da "Revolução de 1964". Segundo Tarso Dutra,

após assegurar o restabelecimento da ordem no país, (a suposta Revolução) incluíra entre os seus superiores objetivos a instituição de um órgão destinado a orientar o governo nas providências fundamentais em favor da cultura. (DISCURSO..., 1968, p. 7).

O ministro insistiu sobre a "vocação democrática do país", assegurada pela Constituição Federal. É curioso observarmos como o discurso de Tarso Dutra incorpora as linhas de ação propostas pelos intelectuais do CFC, como a valorização dos aspectos regionais; a importância dos Conselhos Estaduais de Cultura na construção de uma infraestrutura capaz de gerenciar os problemas do setor; e a necessidade de um levantamento dos problemas da cultura em busca de soluções. Essa proximidade entre os discursos dos conselheiros e do ministro atesta novamente a força política do CFC no interior do Ministério da Educação e Cultura. Cabe ressaltar que Josué Montello, além de criador e presidente do CFC, prestava assessoria ao ministro. Ao final do encontro ficou definido que as verbas do MEC destinadas à cultura só seriam liberadas mediante a realização de convênios entre 0 CFC e os conselhos ou secretarias estaduais de cultura. 
A reunião não resultou em nenhum documento capaz de orientar as ações em favor da cultura. Naquele momento, sua função política foi reunir representantes de estados, municípios e união para divulgarem os dados relativos à situação do patrimônio cultural em cada localidade e as necessidades mais urgentes. Em 1970, o CFC, diante da necessidade de organizar um documento de compromisso sobre a urgência de investimentos na proteção do patrimônio e definir a participação de cada esfera do executivo, articulou um novo encontro em Brasília.

\subsection{O "Encontro sobre a Defesa do Patrimônio Histórico e Artístico Nacional"} (1970)

O "Encontro dos Governadores sobre a Defesa do Patrimônio Histórico e Artístico do Brasil", realizado em Brasília, entre 1 e 3 de abril de 1970, foi coordenado por Arthur Cezar Ferreira Reis, presidente do Conselho, e Pedro Calmon, presidente da Câmara de Patrimônio Histórico e Artístico Nacional do CFC. A iniciativa deste primeiro encontro foi do próprio ministro Jarbas Passarinho (1969-1974). A revista Cultura, n. 34, foi inteiramente dedicada ao evento que contou também com a participação do Almirante Augusto Radmaker, vice-presidente da República, ministro Iberê Gilson, presidente do Tribunal de Contas da União, Renato Soeiro, diretor do Patrimônio Histórico e Artístico Nacional, D. José Newton, arcebispo de Brasília, além de governadores, representantes dos governos dos estados e outras autoridades.

No discurso inaugural, Jarbas Passarinho ressalta que o "Encontro" trataria do conceito de patrimônio em suas diversas ramificações, ou seja, "não só o patrimônio artístico, não só o patrimônio histórico, não só o patrimônio cultural, não só o patrimônio natural, mas todo o patrimônio da Nação e da gente brasileira [...]" (PASSARINHO, 1970, p. 8). Para o ministro, além dos poucos recursos destinados à preservação, o descaso do cidadão brasileiro com sua história aliado à falta de civismo impediam o culto aos monumentos, verdadeiros documentos da nação brasileira. As autoridades ali reunidas deveriam buscar alternativas para solucionar o descaso das autoridades públicas e também da população que não só ameaçava como já comprometia o patrimônio com perdas irreparáveis. $O$ ministro Jarbas Passarinho esperava que aquela reunião fosse uma resposta aos constantes ataques da imprensa ao governo sobre o assunto, lembrando da notícia de um 
periódico dominical que informara a respeito da situação do patrimônio no país: "Brasil, um passado sem futuro" (PASSARINHO, 1970, p. 24).

O diretor da Diretoria do Patrimônio Histórico e Artístico Nacional (DPHAN), antigo SPHAN, conselheiro Renato Soeiro, ficou responsável por apresentar aos presentes os pontos centrais do "Encontro", lembrando da atuação de Rodrigo Melo Franco de Andrade na diretoria daquele órgão: "habituamo-nos a não fazer distinção entre Patrimônio e Rodrigo. As duas imagens para os seus Companheiros de trabalho e amigos se confundem em uma só" (SOEIRO, 1970, p. 14).

Dessa forma, a ideia de patrimônio presente naquela reunião seguia as diretrizes cristalizadas pela ação de Rodrigo Melo Franco de Andrade durante os trinta anos em que dirigiu o SPHAN. Para Soeiro, o patrimônio brasileiro contava com uma avançada legislação criada a partir de 1937 que seria completada quando o Congresso Nacional votasse o projeto do CFC que previa uma série de medidas de controle sobre os usos dos acervos e conjuntos arquitetônicos considerados históricos, além de tratar da criação de estímulos financeiros destinados à sua preservação.

Renato Soeiro destacou a importância da participação dos estados e municípios na proteção do patrimônio regional, através da criação de órgãos semelhantes à DPHAN. Até aquele momento, apenas os estados da Bahia, Guanabara, São Paulo, Paraná e Minas Gerais já possuíam órgãos especializados que funcionavam articulados com a DPHAN. Soeiro reconhecia a dificuldade de preservar os conjuntos arquitetônicos diante das pressões provocadas pela urbanização e modernização das cidades. Para o diretor da DPHAN, a proteção do patrimônio nacional e regional dependia do reconhecimento do poder público e dos grupos sociais da importância daquele acervo histórico para a nação, e sua capacidade de gerar desenvolvimento através do investimento no turismo. A associação preservação-turismo foi a resposta encontrada pelos órgãos de defesa do patrimônio cultural contra o discurso daqueles setores que sob a égide do crescimento econômico e ampliação da infraestrutura do país pressionavam o governo federal a autorizar intervenções drásticas nos conjuntos arquitetônicos e reservas naturais já preservados. Dessa forma, a política de proteção não aparecia como obstáculo ao 
processo de desenvolvimento econômico, ao contrário, movimentava positivamente a economia do país pelos recursos gerados com o turismo.

\begin{abstract}
As iniciativas visando o desenvolvimento dos centros urbanos e rurais, seu aproveitamento turístico e cultural, a exploração racional das florestas, são perfeitamente conciliáveis com a proteção e a revalorização da paisagem, dos monumentos e demais bens de valor histórico e artístico localizados nessas áreas, desde que respeitada a legislação específica vigente e judiciosamente projetados os respectivos planos diretores. Conciliáveis e desejáveis, pois de conseqüências propícias à economia do país, que certamente se beneficiará de uma política inteligente de exploração de suas riquezas naturais, culturais e turísticas. (SOEIRO, 1970, p. 15).
\end{abstract}

A relação entre "preservação e desenvolvimento" identificada através do turismo, obrigou a redefinição do uso dos espaços preservados, necessariamente resignificados ao adquirirem uma nova função social, tornando-os novamente úteis à sociedade moderna, sem com isso deixar de registrar a sua memória. Tratava-se, então, de uma política de proteção e revalorização.

\footnotetext{
O aproveitamento dos monumentos disponíveis de arquitetura civil, militar e religiosa tem sido preocupação constante da DPHAN, pois não basta restaurá-los, - é necessário usá-los adequadamente tais como sedes de museus, casa históricas de cultura ou outras atividades ligadas de preferência, aos planos de cultura ou ensino o que não obsta que possam ser aproveitadas também em "pousadas", no plano econômico. Visa essa orientação, não só garantir-lhes a preservação, mas também uma destinação atuantes na sociedade contemporânea. (SOEIRO, 1970, p. 17).
}

Após a cerimônia de abertura, foram discutidos os seguintes temas: "criação dos patrimônios estaduais" e sua função como órgãos congêneres à DPHAN; a formação de recursos humanos especializados em restauração, identificação e catalogação de acervos; dotação orçamentária e captação de recursos. O primeiro trabalho apresentado foi o do CFC, "Defesa do patrimônio histórico, artístico e natural do Brasil, no pensamento do Conselho Federal de Cultura”. O título do trabalho inicialmente induz no leitor a expectativa de que o CFC apresentaria seus posicionamentos políticos e o aparato conceitual utilizado. Contudo, o documento foi organizado em doze pequenos tópicos distribuídos em ordem numérica e não possui nenhuma apresentação inicial ou conclusão final. Tal estratégia conduz o leitor e os 
ouvintes a uma hierarquização dos temas retratados durante a sua leitura. A opção pela síntese expõe também uma segunda estratégia: destacar pragmaticamente as medidas a serem adotadas, afastando-se das tradicionais discussões conceituais ou políticas, apresentando o documento como uma série de medidas técnicas, racionais e, por isso, aparentemente desprovidas de inserções ideológicas. Dentre as propostas previa-se a criação de órgãos regionais dedicados à proteção do patrimônio histórico e artístico, nos moldes da DPHAN; dotação orçamentária dos estados da federação e a participação da União em programas nacionais; formação de equipe técnica nos estados; infraestrutura estadual, com a criação de arquivos, bibliotecas, Casas de Cultura, museus e parques; restauração dos bens tombados; defesa dos monumentos funerários; ampliação da legislação sobre a comercialização das obras de arte; elaboração de uma legislação que estimule a preservação de bens tombados pelos proprietários; encontros anuais entre os órgãos estaduais e a DPHAN; auxílio técnico e financeiro aos municípios possuidores de conjuntos arquitetônicos tombados. Por fim, o documento recomendava que a adoção dessas medidas ocorresse por

[...] convênios entres os Estados, órgãos da administração pública federal especializados, Ministério da Educação e Cultura através da Diretoria do Patrimônio Histórico e Artístico Nacional e do Conselho Federal de Cultura. (CONSELHO FEDERAL DE CULTURA, 1970a, p. 128)

No segundo dia do encontro, os temas abordaram os "problemas de defesa e utilização do Patrimônio Cultural" e a "defesa do patrimônio natural", destacando a importância do envolvimento dos órgãos federais, estaduais e municipais, além do poder legislativo e judiciário, e das universidades, para melhor gerenciamento e controle dos usos desse patrimônio. Vários representantes de estados se pronunciaram sobre a situação do patrimônio em cada região, apresentando os programas realizados. O secretário de educação e cultura de Minas Gerais, Heráclito Mourão Miranda propôs a realização de estudos sobre os bens imateriais de cada estado, especialmente, o folclore. O espaço dedicado pelo secretário ao tema do folclore surpreende, pois, neste encontro, privilegiou-se o patrimônio de pedra e cal, seguido dos acervos artísticos e documentais. O terceiro dia foi 
dedicado exclusivamente à aprovação do documento Compromisso de Brasília e à cerimônia de encerramento.

Os participantes do Encontro assinaram o Compromisso de Brasília, redigido por Pedro Calmon, documento-síntese dos trabalhos realizados. O documento apresentava vinte três tópicos, ressaltando a "inadiável necessidade" de estados e municípios adotarem medidas como: complementar a ação federal na proteção dos bens culturais e naturais nacionais e regionais através da criação de órgãos específicos sob orientação da DPHAN; elaborar uma legislação estadual e municipal para o setor; ampliar os recursos orçamentários; investir na formação de mão-deobra especializada sob orientação de órgãos federais; proteção da documentação através da criação de arquivos; preservação dos cemitérios e túmulos de valor histórico; criação de museus regionais com a função precípua de documentar "[...] a formação histórica, tendo em vista a educação cívica e o respeito da tradição" (CONSELHO FEDERAL DE CULTURA, 1970b, p. 113). O Compromisso incorporou os principais tópicos do trabalho apresentado pelo CFC durante o "Encontro". Contudo, o Compromisso de Brasília era mais superficial do que o trabalho "Defesa do patrimônio histórico, artístico e natural do Brasil, no pensamento do Conselho Federal de Cultura". O Compromisso de Brasília não tratava do problema das fontes orçamentárias; não mencionava a necessidade de convênios entre os órgãos federais, estaduais e municipais; e não previa a criação de órgãos regionais dedicados exclusivamente à proteção do patrimônio histórico e artístico nacional. Dos vinte três tópicos presentes no Compromisso apenas dois são desconsiderados pelo documento produzido pelo CFC: a necessidade de proteção do patrimônio militar e eclesiástico, e o papel do ensino na formação cívica do cidadão.

Os integrantes do CFC vinculavam a identidade nacional às comemorações históricas, à defesa do patrimônio e às manifestações artísticas populares, numa releitura e ampliação das políticas culturais realizadas pelo Estado Novo (19371945). A valorização da memória nacional ocorreria através da institucionalização da cultura e da revitalização do patrimônio histórico e artístico cujos maiores exemplos são a criação de um conjunto comemorativo de efemérides e o investimento em políticas de proteção do patrimônio. 
A descrição objetiva dos elementos simbólicos que compõem e singularizam a nação são mais eficientes quanto maior a capacidade de gerar percepções homogêneas do grupo ao qual se pretende consolidar o sentimento de pertencimento. Assim, a cultura brasileira só existe no interior da nação e só é verdadeira quando corresponde aos interesses de todos os setores sociais, ou seja, é marcada pelo desinteresse, pois não serve a nenhum grupo em particular, respondendo aos elementos condicionantes e dinâmicos que a promovem. Toda cultura, nesta perspectiva, tem um caráter nacional, pois seu desenvolvimento depende de fatores geográficos, da herança étnica, dos momentos históricos e da linguagem vivenciados por um grupo social.

\section{Novos tempos no setor cultural: o esgotamento político do Conselho Federal de Cultura}

O Conselho Federal de Cultura, entre 1967 e 1975, promoveu convênios; financiou projetos; investiu na publicação de obras de referência sobre a cultura nacional; e, propôs importantes anteprojetos de lei para a institucionalização do setor cultural e reformulação de suas principais instituições. A capacidade de execução dos inúmeros projetos criados pelo Conselho sempre foi limitada, especialmente, devido aos seus poucos recursos. Entretanto, a vitalidade política desta instituição só apresentou sinais de esgotamento, em meados da década de 1970, quando uma nova proposta para o setor cultural avançou pelo aparelho estatal e o investimento maciço na produção cultural foi vislumbrado como a melhor opção para responder ao processo de desenvolvimento almejado pelo executivo.

Em 1973, durante a cerimônia de posse dos novos presidente e vice-presidentes do CFC, respectivamente, Raymundo Moniz de Aragão e Manuel Diégues Júnior, para o biênio de 1973/1974, o conselheiro Arthur Cezar Ferreira Reis, ao se despedir da presidência do Conselho, cargo que ocupou durante quatro anos (1969-1972), aproveitou a rara presença do ministro da Educação e Cultura no plenário do CFC, para discursar sobre as limitações da intervenção estatal no setor e a importância da cultura no desenvolvimento estrutural da nação. Certo da existência de uma cultura brasileira, forjada neste "continente-arquipélago", carente de ser preservada, e do seu caráter de patrimônio da nação, Arthur Reis ressentia-se da fragilidade das políticas culturais brasileiras: 
O que podemos considerar como política cultural, todavia, é ainda um tanto tímido como exteriorização de um propósito, de uma decisão, de uma orientação perseguida incessantemente e executada através de atos permanentes e não acidentais. (REIS, 1973, p. 13).

Com a posse do ministro da Educação e Cultura Ney Braga, em 3 de abril de 1974, a ação do Estado no setor cultural sofreria profundas alterações. Ao invés do Plano Nacional de Cultura, uma "Política Nacional de Cultura", também identificada pela sigla PNC, foi aprovada em 1975, durante a gestão Ney Braga. Elaborada pelo grupo-tarefa responsável pelo Programa de Ação Cultural - PAC, a Política Nacional de Cultura foi vinculada ao Departamento de Ações Culturais. Sobre esta PNC, nos informa Isaura Botelho, a partir do depoimento de Roberto Parreira, coordenador do PAC e um dos idealizadores da nova política:

Ele afirma que desde sua fundação, em 1966, o Conselho Federal de Cultura havia apresentado dois ou três planos nacionais de cultura, que não foram muito além da apresentação do ministro da época. Nei Braga inverteu o processo: ao invés de solicitar ao Conselho mais um plano, ele solicitou a um grupo de técnicos a formulação de uma política para nortear a sua gestão, para submetê-la, a posteriori, à homologação do Conselho. (BOTELHO, 2000, p. 67).

Assim, a Política Nacional de Cultura adotada foi formulada pelo grupo gestado no interior do DAC, a partir do lançamento do Plano de Ação Cultural, em agosto de 1973. Foi um duro golpe nas pretensões políticas do CFC. A aprovação da Política Nacional de Cultura elaborada e subordinada a outro órgão do MEC não deixava dúvidas: o CFC não tinha mais legitimidade política e administrativa para organizar as políticas culturais brasileiras. Fragilizado, cabia ao Conselho a função normativa e fiscalizadora, limitando-se à categoria administrativa na qual se enquadrava, apesar das intervenções executivas realizadas naqueles últimos nove anos. A correlação de forças políticas no interior do MEC havia mudado.

A gestão Ney Braga iniciou uma nova fase no setor cultural (CALABRE, 2009, p. 78) empurrando para o ostracismo os projetos defendidos pelos velhos modernistas, e 
trazendo para o interior do MEC outra percepção sobre como gerenciar as políticas culturais brasileiras, afinal:

Essa ideologia tradicional não seria adequada ao desenvolvimento do capitalismo que tem o Estado como promotor da racionalidade e da técnica. Há necessidade de contar com um novo intelectual e com um novo aparato organizacional [...]. (OLIVEIRA, 2007, p. 138).

Os técnicos, tão criticados pelos conselheiros pela postura racionalista, pelo precário domínio dos conhecimentos humanísticos, considerado necessário à formulação de políticas no setor cultural, foram agentes importantes na dinamização do setor a partir de 1975, especialmente na elaboração do documento "Política Nacional de Cultura".

A partir do lançamento oficial da Política Nacional de Cultura organizada pelos técnicos do PAC, o CFC viu minguar seu espaço de intervenção política. Soma-se a isso a criação de novas agências e instituições no interior do aparelho estatal, a partir de 1975, como a Fundação Nacional de Arte (FUNARTE); Conselho Nacional de Cinema (Concine); Conselho Nacional de Referência Cultural (CNRC); Secretaria de Assuntos Culturais (SEAC); Fundação Nacional Pró-Memória (Pró-Memória); entre outras - algumas inclusive fora da órbita do MEC. O CFC ainda seria o responsável pela organização do "I Encontro dos Secretários Estaduais de Cultura", em Brasília, no ano de 1976. Entretanto, com o aparecimento de novas instituições com atribuições definidas e multifacetadas, o CFC passou a disputar espaço político que antes dominava, mesmo com restrições financeiras, vendo sua atuação limitada por força de lei, mas, fundamentalmente, pelos novos grupos que exigiam a clara demarcação das funções de cada setor do MEC. As novas instituições mostram o impulso dado ao setor cultural a partir de 1975, acentuado graças à gestão Ney Braga. A partir de 1976, muitos outros intelectuais passaram pelo Conselho, dificultando a coesão do grupo nuclear do CFC. Doravante, o silêncio em torno do Conselho pode ser compreendido pela tentativa dos novos grupos em torno do MEC de caracterizarem como política cultural e sistematização eficaz do setor apenas as ações executadas a partir de 1975. Contudo, o CFC foi o órgão responsável por intervenções sistemáticas que produziram no interior do aparelho estatal uma rotina burocrática fundamental na institucionalização do setor. De toda forma, com a 
gestão Ney Braga, o Conselho tornou-se mais contemplativo do que produtor dos rumos da política cultural. O CFC permaneceria em funcionamento até 1990, quando foi extinto, mas sem a pujança vivenciada nos anos anteriores.

\section{Conclusão}

Os intelectuais do Conselho Federal de Cultura, entre 1967 e 1975, foram responsáveis pela orientação das políticas culturais, atuando, especialmente, na proteção e divulgação do patrimônio cultural. Investiram os recursos disponíveis no financiamento de reformas estruturais e nos projetos das instituições nacionais de cultura; na defesa dos conjuntos arquitetônicos; na recuperação de arquivos documentais e bibliotecas; na criação de centros culturais nos pequenos e médios municípios; nas comemorações de efemérides; na publicação de obras de caráter literário ou histórico que descortinassem a "essência" da cultura nacional.

A força política do Conselho consistiu na sua capacidade de intervenção justamente num período onde a área cultural foi relegada ao segundo plano pelo governo e limitada pelas reduzidas verbas orçamentárias. Desde a década de 1930, os intelectuais do CFC atuaram no Ministério da Educação e Cultura executando o projeto modernista. Trouxeram para o centro das políticas culturais, o "espírito da nacionalidade" tão veiculado durante o Estado Novo através da valorização do folclore, do passado histórico, da literatura nacional, da arquitetura histórica, forjando, a partir de então, a "consciência nacional". Esse conjunto formava o patrimônio cultural que traduzia a experiência do ser brasileiro.

A criação do CFC possibilitou às instituições nacionais, estaduais e municipais a manutenção de muitas de suas atividades, além de construir uma rotina para o setor até então limitada, através do estímulo à criação de conselhos estaduais e municipais de cultura; à elaboração de anteprojetos de lei para a reformulação do setor cultural; à realização de encontros com governadores, ministros e secretários para formulação de uma política integrada com co-responsabilidade de estados e municípios; à criação de um ministério dedicado exclusivamente à cultura; à edição de obras já esgotadas sem interesse mercadológico, mas com valor histórico. A proteção do patrimônio cultural, em suas diversas acepções, sempre ameaçado pelo descaso, foi uma área de atuação constante dos membros do Conselho. As 
realizações do Conselho não devem ser descartadas, nem minimizadas diante da dinamização do setor cultural promovida pelo Estado na década de 1970 e realizada por outros grupos no interior do aparelho estatal. Ao contrário, as propostas e políticas empreendidas pelo CFC devem ser compreendidas neste processo histórico específico de participação dos intelectuais no cenário político como portadores dos anseios nacionais e que atravessou governos legitimamente constituídos ou não para forjar os rumos da Nação.

\section{Referências bibliográficas}

BOLETIM do Conselho Federal de Cultura. Rio de Janeiro, RJ: O Conselho, v. 1-20, 1967-1970.

BOTELHO, Isaura. Romance de formação: Funarte e política cultural 1976-1990. Rio de Janeiro: Edições Casa de Rui Barbosa, 2000.

BRASIL. Documento de Brasília. Cultura. Brasília, DF: Ministério da Educação e Cultura, v. 4, n. 34, p. 111-115, abr. 1970.

CALABRE, Lia. Políticas culturais no Brasil: dos anos de 1930 ao século XXI. Rio de Janeiro: FGV, 2009.

CONSELHO FEDERAL DE CULTURA. Cultura. Brasília, DF: Ministério da Educação e Cultura, v. 4, n. 34, p. 127-128, abr. 1970.

CONSELHO FEDERAL DE CULTURA. Diretrizes para uma Política Nacional de Cultura. Boletim do Conselho Federal de Cultura. Rio de Janeiro, RJ: O Conselho, n. 9, p. 57-64, jan./mar. 1973.

CONSELHO FEDERAL DE CULTURA. Compromisso de Brasília. Cultura. Brasília, DF: Ministério da Educação e Cultura, v. 4, n. 34, p. 111-115, abr. 1970.

DECRETO-LEI n. 74 de 21 de novembro de 1966. "Cria o Conselho Federal de Cultura e dá outras providências". Cultura. Brasília, DF: Ministério da Educação e Cultura, v. 1, n. 1, p. 107-110, jul. 1967.

DECRETO n. 62.256 de 12 de fevereiro de 1968. Publicado no Diário Oficial de 15 de fevereiro de 1968. Cultura. Brasília, DF: Ministério da Educação e Cultura, v. 2, n. 7, p. 67, jan. 1968.

DISCURSO do Ministro da Educação e Cultura, Deputado Tarso Dutra. Cultura. Brasília, DF: Ministério da Educação e Cultura, v. 2, n. 10, p. 7-9, abr. 1968.

FALCÃO, José Arruda. Política cultural e democracia: a preservação do patrimônio histórico e artístico nacional. In: MICELI, Sérgio (Org.). Estado e cultura no Brasil. São Paulo, DIFEL, 1984. p. 21-40. 
FONSECA, Maria Cecília de Londres. O patrimônio em processo: trajetória da política federal de preservação no Brasil. 2. ed. Rio de Janeiro: Editora UFRJ/MinC/IPHAN, 2005.

GARCÍA CANCLINI, Nestor. Culturas híbridas. São Paulo: Edusp, 2000.

Políticas culturales en América Latina. México, D.F.: Grijalbo, 1987.

GOMES, Angela Maria de Castro. História e historiadores. Rio de Janeiro: FGV, 1996.

GONÇALVES, José Reginaldo Santos. A retórica da perda: os discursos do patrimônio cultural no Brasil. Rio de Janeiro: Editora UFRJ/IPHAN, 1996.

MACHADO, Mário Brockmann. Estado e cultura no Brasil. In: VILLAS BÔAS, Glaúcia; GONÇALVES, Antonio (Org.). O Brasil na virada do século: o debate dos cientistas sociais. Rio de Janeiro: Relume Dumará, 1995. p. 268-271.

MAIA, Tatyana de Amaral. Cardeais da cultura nacional: o Conselho Federal de Cultura e o papel cívico das políticas culturais na ditadura civil-militar (1967-1975). 2010. Tese (Doutorado)-Programa de Pós-graduação em História (PPGH-UERJ), Universidade Estadual do Rio de Janeiro, Rio de Janeiro, mar. 2010.

MICELI, Sérgio. O processo de "construção institucional" na área cultural federal (anos 70). In: (Org.). Estado e Cultura no Brasil. São Paulo: DIFEL, 1984. p. 53-84.

MINISTÉRIO da Educação e Cultura. Política Nacional de Cultura. Brasília: Departamento de Documentação e Divulgação, 1977.

OLIVEIRA, Lúcia Maria Lippi. Cultura é patrimônio. Um guia. Rio de Janeiro: FGV, 2008. Política nacional de cultura: dois momentos em análise - 1975 e 2005. In: GOMES, Angela de Castro. Direitos e cidadania: memória, política e cultura. Rio de Janeiro: FGV, 2007. p. 137-154.

ORTIZ, Renato. Cultura brasileira e identidade nacional. São Paulo: Brasiliense: 1986.

PASSARINHO, Jarbas. Discurso do Ministro Jarbas Passarinho. Cultura. Brasília, DF: Ministério da Educação e Cultura, v. 4, n. 34, p. 7-24, abr. 1970.

REIS, Arthur Cezar. Discurso realizado por Arthur C. F. Reis durante a cerimônia de posse do Prof. Raymundo Moniz de Aragão da presidência do Conselho Federal de Cultura. Boletim do Conselho Federal de Cultura. Rio de Janeiro, RJ: O Conselho, n. 9, p. 11-24, jan./mar. 1973.

SCHWARTZMAN, Simon; BOMENY, Helena Maria Bousquet; COSTA, Vanda Maria Ribeiro. Tempos de Capanema. São Paulo: Paz e Terra; FGV, 2000.

SEVCENKO, Nicolau. A literatura como missão: tensões sociais e criação cultural na Primeira República. São Paulo: Brasiliense, 1983. 
SOEIRO, Renato. Discurso proferido no I Encontro sobre defesa do Patrimônio Histórico e Artístico Nacional. Cultura. Brasília, DF: Ministério da Educação e Cultura, v. 4, n. 34, p. 13-22, abr. 1970.

\section{Créditos}

Doutora em História e professora adjunta da Universidade Severino Sombra (USS) de Vassouras/RJ. e-mail: tatyanamaia@yahoo.com.br

artigo recebido em 05/2010

artigo aprovado em 10/2010 